\title{
One-pot, four-component synthesis of pyrano[2,3-c]pyrazoles catalyzed by sodium benzoate in aqueous medium
}

\author{
Hamzeh Kiyani $^{a^{*}}$, Heshmat Allah Samimi ${ }^{b}$, Fatemeh Ghorbani ${ }^{a}$ and Samira Esmaielia
}

${ }^{a}$ School of Chemistry, Damghan University, 36715-364, Damghan, Iran

${ }^{b}$ Faculty of Science, Department of Chemistry, Shahrekord University, P. O. Box 115, Shahrekord, Iran

\section{H R O N I C L E}

Article history:

Received March 20, 2013

Received in Revised form July 7, 2013

Accepted 10 July 2013

Available online

12 July 2013

\section{Keywords:}

Pyrano[2,3-c]pyrazole

Four-component reaction

Sodium Benzoate

aqueous medium

\section{Introduction}

2-Amino-4-substituted pyrano[2,3-c]pyrazole-3-carbonitriles (pyranopyrazoles) are an important category of heterocyclic compounds, which play a significant role in pharmaceutical field and biologically active compounds. Compounds bearing pyranopyrazole system have been found to have various biological activities, for instance antimicrobial, ${ }^{1}$ analgesic, ${ }^{2}$ vasodilator, ${ }^{3}$ anticancer,,${ }^{4,5}$ antiinflammatory, ${ }^{6}$ inhibitors of human Chk1 kinase, ${ }^{7}$ molluscicidal, ${ }^{8}$ antifungicidal, ${ }^{9}$ and also as biodegradable agrochemicals, ${ }^{10}$ Furthermore, some of these compounds are commonly in employment such as cosmetics and pigments. ${ }^{11}$

Pyranopyrazoles were first obtained in 1973 by reaction between 3-methyl-1-phenylpyrazolin-5one and tetracyanoethylene. ${ }^{12}$ The 2-amino-4-substituted pyrano[2,3-c]pyrazole-3-carbonitriles were

* Corresponding author.

E-mail addresses: hkiyani@du.ac.ir (H. Kiyani)

(C) 2013 Growing Science Ltd. All rights reserved. doi: $10.5267 /$ j.ccl.2013.07.002
An efficient, green, and facile four-component reaction for the preparation of pyrano[2,3c]pyrazole derivatives through the condensation reaction of aryl aldehydes, ethyl acetoacetate, malononitrile, and hydrazine hydrate or phenyl hydrazine in the presence of commercially available organocatalyst sodium benzoate under aqueous condition is reported. The products are environmental friendly. 
obtained in 1974 by addition of malononitrile to 4-arylidene-3-methyl-2-pyrazolin-5-one. ${ }^{13}$ Afterwards several other synthetic approaches to synthesis of these compounds were reported. These approaches include one-pot three-component condensation of pyrazolone derivatives, malononitrile, and aromatic aldehydes or pyrazole-aldehydes; ${ }^{14}$ three-component cyclocondensation of substituted piperidin-4-ones, pyrazol-5-ones, and malononitrile; ${ }^{15}$ four-component reaction of aldehydes, ethyl acetoacetate, malononitrile with hydrazine hydrate; ${ }^{16-18,20-32}$ two-component reaction of 3-methyl-2pyrazolin-5-one with benzylidenemalononitriles; ${ }^{19}$ and four-component reaction involving aromatic aldehydes, Meldrum's acid, hydrazine hydrate, and ethyl acetoacetate. ${ }^{32}$ Various catalysts and conditions have been used to synthesis pyranopyrazoles, via reactions mentioned above.Some of those catalyst are triethylamie in ethanol or water, ${ }^{14 a, 15} p$-dodecylbenesulfonic acid (DBSA) in water at $60{ }^{\circ} \mathrm{C},{ }^{14 \mathrm{c}}$ hexadecyltrimethylammonium bromide (HTMAB) at $60-80{ }^{\circ} \mathrm{C},{ }^{14 \mathrm{~d}}$ ammonium acetate in ethanol, ${ }^{14 \mathrm{~g}}$ triethylbenzylammonium chloride (TEBACl) at $90^{\circ} \mathrm{C}$ in water solution, ${ }^{14 i} \beta$-cyclodextrin in water, ${ }^{16}$ imidazole in aqueous medium, ${ }^{17}$ piperidine in ethanol or water, ${ }^{14 \mathrm{~h}, 18}$ cinchona alkaloid organocatalysts in dichloromethane, ${ }^{19}$ per-6-amino- $\beta$-cyclodextrin (per-6-ABCD),${ }^{20}$ Brønsted-acidic ionic liquid under solvent-free conditions, ${ }^{21}[\mathrm{bmim}] \mathrm{OH},{ }^{22}$ L-proline and $\gamma$-alumina, ${ }^{23}$ silicotungstic acid $\left(\mathrm{H}_{4}\left[\mathrm{SiW}_{12} \mathrm{O}_{40}\right]\right),{ }^{24}$ glycine, ${ }^{25} \mathrm{NaOH}$ in EtOH under microwave irradiation, ${ }^{26}$ dodecyltrimethylammonium bromide, ${ }^{27}$ iodine in water, ${ }^{28} \mathrm{~L}$-proline at $50{ }^{\circ} \mathrm{C}$ in $[\mathrm{Bmim}] \mathrm{BF}_{4},{ }^{29}$ silica in water, ${ }^{30}$ nanostructured $\mathrm{MgO},{ }^{31} \mathrm{Ba}(\mathrm{OH})_{2}$ in water at reflux, ${ }^{32}$ and cetyltrimethylammonium chloride $(\mathrm{CTACl}){ }^{33}$ Other non-catalytic methods were also applied for the synthesis of these compounds. For example there were synthesis in aqueous ethanol at $100{ }^{\circ} \mathrm{C}$ for $2.5 \mathrm{~h},{ }^{6 \mathrm{c}, 34}$ fourcomponent reaction in boiling water for $2-6 \mathrm{~h},{ }^{35}$ ultrasound activated reaction, ${ }^{14 \mathrm{j}}$ synthesis under microwave irradiation, ${ }^{36}$ and reaction in solvent-free conditions. ${ }^{37}$ All listed above methods suffer from one or more drawbacks such as prolonged reaction time, use of organic solvents, strong acid or base catalysts, ionic liquids, required special apparatus (e.g., microwave and ultrasound irradiation), and harsh reaction conditions procedures. Thus, the development of new environmental friendly, more effective procedure for the synthesis of pyranopyrazoles and carrying out organic reactions in water is of significant interest.

Water, due to features such as ecological friendly, safe, non-toxic, non-flammable, clean, green, inexpensive as well as readily available has been recommended to be used as a solvent in organic syntheses. ${ }^{14,38-43}$ Sodium benzoate is a readily accessible commercially material, and has been used in cosmetics and pharmaceutical industry. This compound is also well known for their application in food industry as a safe preservative and antimicrobial agent. Literature survey also reveals that sodium benzoate has been employed as an eco-friendly base catalyst for the synthesis of cyclic ketones, ${ }^{44}$ arylmethylene isoxazol-5(4H)-ones, ${ }^{45}$ and substituted olefins via Knoevenagel condensation. ${ }^{46}$

In consideration of green chemical methodology, here we report the synthesis of pyranopyrazoles (5) starting from aryl aldehydes (1), hydrazines (2), ethyl acetoacetate (3), and malononitrile (4) using sodium benzoate as the mild basic catalyst in water (Scheme 1).

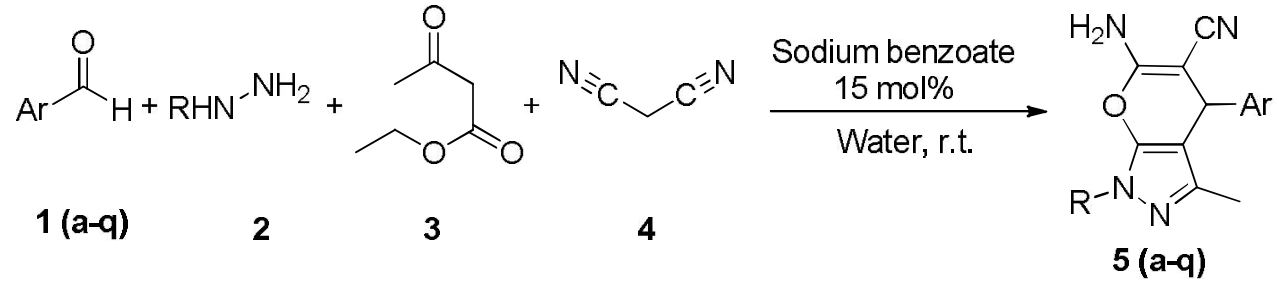

R: $\mathrm{H}, \mathrm{Ph}$

Ar: $\mathrm{C}_{6} \mathrm{H}_{5}, 4-\mathrm{NO}_{2} \mathrm{C}_{6} \mathrm{H}_{4}, 3-\mathrm{NO}_{2} \mathrm{C}_{6} \mathrm{H}_{4}, 2-\mathrm{NO}_{2} \mathrm{C}_{6} \mathrm{H}_{4}, 4-\mathrm{CH}_{3} \mathrm{C}_{6} \mathrm{H}_{4}, 4-\mathrm{OCH}_{3} \mathrm{C}_{6} \mathrm{H}_{4}, 4-\mathrm{OHC}_{6} \mathrm{H}_{4}$, $4-(\mathrm{NMe})_{2}-\mathrm{C}_{6} \mathrm{H}_{4}, 4-\mathrm{ClC}_{6} \mathrm{H}_{4}$.

Scheme 1. One-pot four-component synthesis of pyranopyrazoles (5) 


\section{Results and Discussion}

As an introductory test, we run a model reaction by stirring an equimolecular amounts of 4hydroxybenzaldehyde (1g) with hydrazine hydrate (2a), ethyl acetoacetate (EAA) (3), and malononitrile (4) in the presence of sodium benzoate $(2.5 \mathrm{~mol} \%)$ in water $(5 \mathrm{~mL})$ at $25{ }^{\circ} \mathrm{C}$ that result in the formation of the desired compound $\mathbf{5 g}$ with $45 \%$ yield (Table 1 , entry 1 ). The product was identified by spectral data and mixed melting point with an authentic sample. In order to seek an optimal solvent and optimal amounts of catalyst, the model reaction was explored using different solvents such as water, ethanol, tetrahydrofuran (THF), dichloromethane, chloroform, and mixture of water/ethanol (1:1) at room temperature (Table 1, entries 6-10). Also, in order to optimize the sodium benzoate loading, the model reaction was performed with different amounts of catalyst at ambient temperature. The results are summarized in Table 1.

Table 1. Synthesis of $\mathbf{5 g}$ in the presence of different solvents and amounts of catalyst $\mathrm{t}^{\mathrm{a}}$

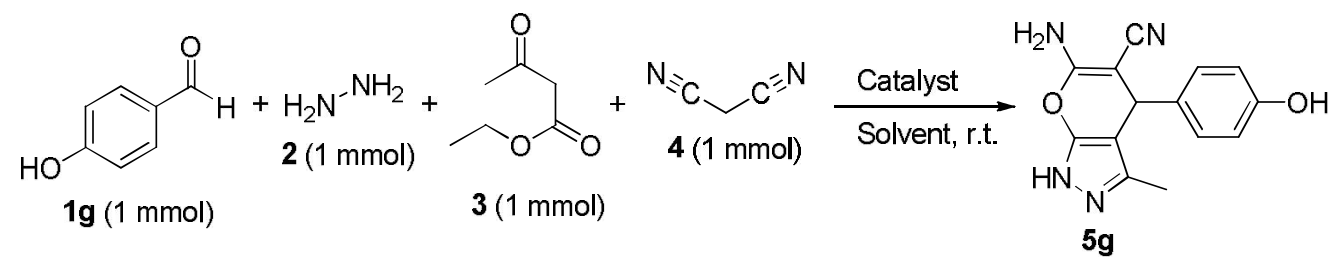

\begin{tabular}{|c|c|c|c|c|}
\hline Entry & Solvent & Amounts of catalyst $(\mathrm{mol} \%)$ & Time (min) & Yield $(\%)^{b}$ \\
\hline 1 & $\mathrm{H}_{2} \mathrm{O}$ & 2.5 & 35 & 45 \\
\hline 2 & $\mathrm{H}_{2} \mathrm{O}$ & 5 & 30 & 53 \\
\hline 3 & $\mathrm{H}_{2} \mathrm{O}$ & 10 & 30 & 84 \\
\hline 4 & $\mathrm{H}_{2} \mathrm{O}$ & 15 & 30 & 90 \\
\hline 5 & $\mathrm{H}_{2} \mathrm{O}$ & 20 & 30 & 81 \\
\hline 6 & $\mathrm{EtOH}$ & 15 & 35 & 46 \\
\hline 7 & $\mathrm{CH}_{2} \mathrm{Cl}_{2}$ & 15 & 80 & Trace \\
\hline 8 & THF & 15 & 80 & 15 \\
\hline 9 & $\mathrm{CHCl}_{3}$ & 15 & 80 & Trace \\
\hline 10 & $\mathrm{H}_{2} \mathrm{O}: \mathrm{EtOH}(1: 1)$ & 15 & 35 & 60 \\
\hline
\end{tabular}

It was found that polarity of solvent and presence of sodium benzoate play an important role for the success of the reaction. The results indicated that solvents were also affected on the yield of $\mathbf{5 g}$ (Table 1, entries 4-8). In the organic solvents such as dichloromethane, THF, ethanol, or chloroform, the yield of $\mathbf{5 g}$ were lower and longer reaction times were required, whereas the reaction using water resulted in good yields (Table 1, entries 1-4). Based on the results, water was chosen to be the best in terms of the yield of the product and reaction time in comparison to common organic solvents. From Table 1, we observed that the yield of product $\mathbf{5 g}$ was improved and the reaction time was relatively shortened when the amount of catalyst was increased from $2.5 \mathrm{~mol} \%$ to $15 \mathrm{~mol} \%$ (Table 1, entries $1-4$ ).

After optimization the reaction conditions, the scope of the method was investigated with a series of substituted aromatic aldehydes and phenyl hydrazine. The results are summarized in Table 2. As seen from Table 2, the aromatic aldehydes carrying both electron-withdrawing (Entries 2-4, 9-10, 12 13 and 17) and electron-donating functional groups (Entries 5-8 and 14-16) underwent successful condensation with hydrazine hydrate, EAA, and malononitrile in the presence of catalytic amount of sodium benzoate in water at room temperature to afford the corresponding products in good yields. It seems that the electronic effects and the nature of the substituents on the aryl aldehyde ring have slight effect on both reaction yield and necessary time for the completion of the reaction. The electron-donating groups somewhat increased reactivity and afforded higher yields compared to 
electron-withdrawing groups. In addition, this reaction was affected by steric effect. For example, 2nitrobenzaldehyd (1d) required longer reaction time compared to 4-nitrobenzaldeyde (1b) owing to sterically hindered ortho position, substituted by nitro group 1d. However, when the reaction of phenyl hydrazine was carried out with aryl aldehydes, EAA, and malononitrile, corresponding products were obtained in good yields after longer reaction times, compared to hydrazine hydrate (Table 2, entries 11-17). In this case, the effects of functional groups in the aromatic aldehyde ring were opposite. Remarkably, the reactions were clean and all the products were obtained after only a filtration and simple washing with water and ethanol. Thus, a simple work-up gives the title products without of need of chromatographic purification.

Table 2. Synthesis of 6-amino-4-aryl-3-methyl-1,4-dihhydropyrano[2,3-c]pyrazole-5-carbonitriles (5) ${ }^{\mathrm{a}}$

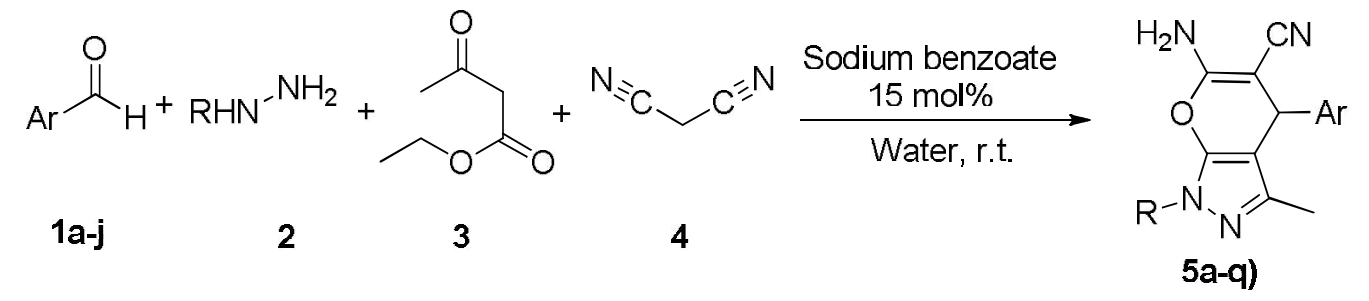

\begin{tabular}{lllllll}
\hline Entry & $2, \mathrm{R}$ & Product & $\begin{array}{l}\text { Time } \\
(\mathrm{min})\end{array}$ & $\begin{array}{l}\text { Yield } \\
(\%)\end{array}$ & \multicolumn{2}{c}{$\begin{array}{l}\text { Mp }\left({ }^{\circ} \mathrm{C}\right) \\
\text { Fit. }\end{array}$} \\
\hline Fef.
\end{tabular}


9

10

11

1j<smiles>O=Cc1ccccc1</smiles>

1a

12<smiles>O=Cc1ccc([N+](=O)[O-])cc1</smiles>

13<smiles>O=Cc1cccc([N+](=O)[O-])c1</smiles>

1c

14<smiles>Cc1ccc(C=O)cc1</smiles>

$1 \mathrm{e}$

15<smiles>COc1ccc(C=O)cc1</smiles>

16

17<smiles>O=Cc1ccc(O)cc1</smiles>

$1 \mathrm{~g}$<smiles>O=Cc1ccc(Cl)cc1</smiles>

$\mathrm{H}$

$5 \mathbf{i}$

60

92

230-232

$233-234^{22}$

$\mathrm{H}$

$\mathrm{Ph}$

$\mathrm{Ph}$

51

$\mathrm{Ph}$

$\mathrm{Ph}$

$\mathrm{Ph}$

$\mathrm{Ph}$

$5 p$

$5 q$

$\mathrm{Ph}$

5j

$5 k$

$5 \mathrm{~m}$

$5 n$

50

45

86

85

45

1i

${ }^{\mathrm{a}}$ Reagents and conditions: aryl aldehyde $\mathbf{1}(1 \mathrm{mmol})$, hydrazine or phenyl hydrazine $\mathbf{2}(1 \mathrm{mmol})$, ethyl acetoacetate $\mathbf{3}(1 \mathrm{mmol})$
mmol), water $(5 \mathrm{~mL})$, room temperature. ${ }^{\mathrm{b}}$ The yields are of pure products obtained after filtrated and recrystallization from ethanol.

A plausible reaction mechanism for this condensation is shown in Scheme 2. On the basis of the chemistry of pyranopyrazoles, it is reasonable to assume that pyrazolone derivative $\mathbf{6}$ was formed by the condensation reaction of hydrazine derivative $\mathbf{2}$ with ethyl acetoacetate 3. Then dicyanoalkene 8 was formed through the reaction base-catalyzed of aryl aldehyde 1 and malononitrile 4 . The next step may involve Michael addition of the methylene group of pyrazolone 7 to an electron deficient carbon of dicyanoalkene $\mathbf{8}$, which gives an intermediate $\mathbf{9}$, leading to cyclic intermediate $\mathbf{1 0}$, followed by $\mathbf{1 0}$ is tautomerized to target pyranpyrazoles $\mathbf{5 a - q}$.

The catalyst can be recovered by evaporation of solvent from filtrated solution after each run and reused. TLC showed that there was no starting materials or product in the filtered solution. All of the substrates were transferred to target products completely. Measuring the melting point of the solid residual after evaporation of the solvent, confirmed the presence of sodium benzoate in the filtrate. The recycled catalyst was applied in four consecutive runs of the same model reaction under the optimized conditions $\left(1^{\text {th }}\right.$ use: $90 \%$, isolated yield, $2^{\text {th }}$ use: $89 \%$ isolated yield, $3^{\text {th }}$ use: $85 \%$ isolated yield, and $4^{\text {th }}$ use: $80 \%$ isolated yield). Decreasing the yield is probably related to slight reduction in the catalytic activity of sodium benzoate or decreasing of amount of recycled catalyst during the handling. 


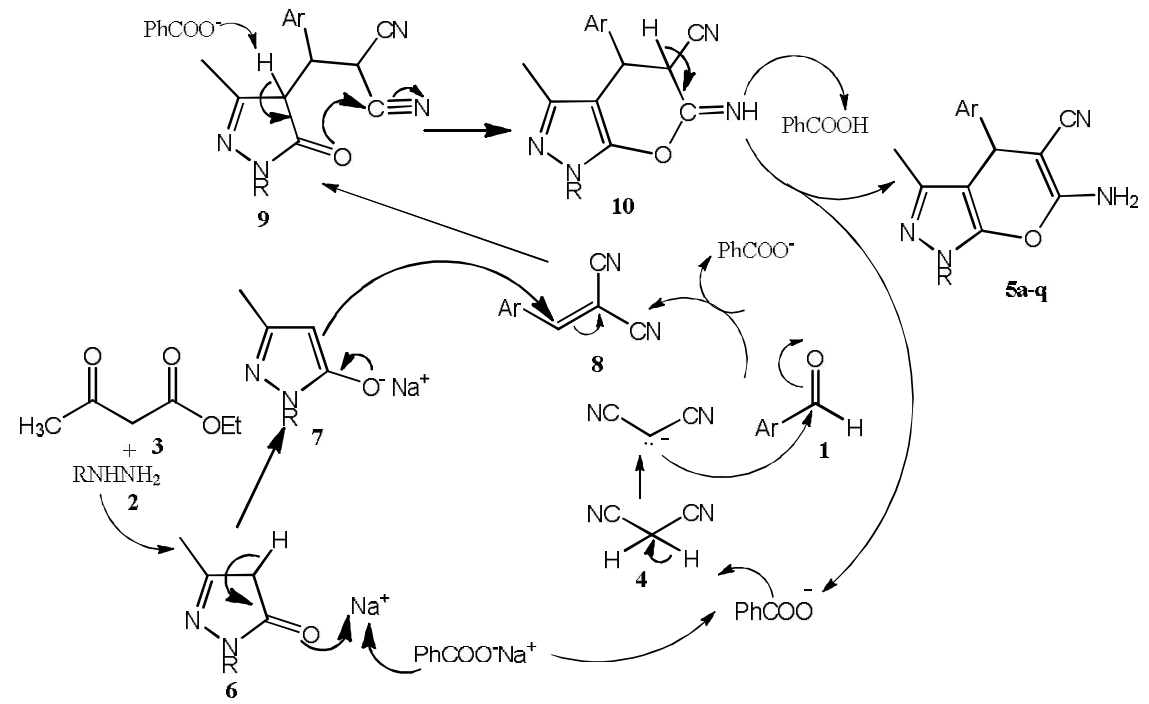

Scheme 2. A proposed mechanism for the four-component synthesis of pyrano[2,3-c]pyrazoles (5a-q).

\section{Conclusions}

In conclusion, we have demonstrated a highly efficient method for the synthesis of pyranopyrazoles via four-component reaction of aromatic aldehydes, malononitrile, ethyl acetoacetate, and hydrazine hydrate or phenyl hydrazine using cheap and readily available low toxic organocatalyst sodium benzoate. The significant advantages of this procedure are operational simplicity, clean reaction, easy preparation and handling of the catalyst, increased safety, and environmental friendly reaction condition.

\section{Acknowledgements}

The authors are thankful to the Research Council of Damghan University.

\section{Experimental}

\subsection{General}

All the reagents and chemicals were obtained from commercial sources and used without further purification. Melting points were measured on a Buchi 510 melting point apparatus and are uncorrected. IR spectra were recorded on a Shimadzu FT-IR 8300 Spectrophotometer using $\mathrm{KBr}$ pellets technique. ${ }^{1} \mathrm{H}$ NMR and ${ }^{13} \mathrm{C}$ NMR spectra were recorded at ambient temperature on a BRUKER AVANCE DRX-400 MHz spectrophotometer using dimethylsulfoxide (DMSO- $d_{6}$ ) as the solvent and TMS as an internal standard. The purity of synthesized compounds as well as a progress of the reactions was monitored by thin layer chromatography (TLC) on Merck pre-coated silica gel $60 \mathrm{~F}_{254}$ aluminum sheets, visualized by UV light.

\subsection{General procedure for preparation of pyrano[2,3-c]pyrazole derivatives}

A mixture of aryl aldehyde 1 ( $1 \mathrm{mmol})$, phenylhydrazine/hydrazine hydrate 2 (1 mmol), ethyl acetoacetate $3(1 \mathrm{mmol})$, malononitrile 4 (1 mmol) and sodium benzoate $(15 \mathrm{~mol} \%)$ was stirred in water $(5 \mathrm{~mL})$ at room temperature for mentioned in Table 2 time. After completion of the reaction (monitored by TLC), the product was filtered off, washed with small amounts of water $(10 \mathrm{~mL})$ and then ethanol $(5 \mathrm{~mL})$ then recrystallized from ethanol to give the pure products $5(\mathbf{a}-\mathbf{q})$. 


\section{Selected Spectral Data}

Compound 5b: IR (KBr) cm $\mathrm{cm}^{-1} 3410,3205,3080,2220,1665,1610,1585,1515,1440,1395,1320$, 1230, 1180, 750; ${ }^{1} \mathrm{H}$ NMR (400 MHz, DMSO-d $d_{6} \delta \mathrm{ppm} 1.77\left(\mathrm{~s}, 3 \mathrm{H}, \mathrm{CH}_{3}\right), 4.79(\mathrm{~s}, 1 \mathrm{H}, \mathrm{CH}), 6.98(\mathrm{~s}$, br, $\left.2 \mathrm{H}, \mathrm{NH}_{2}\right), 7.46(\mathrm{~d}, 2 \mathrm{H}, J=8.4 \mathrm{~Hz}, \mathrm{ArH}), 8.20(\mathrm{~d}, 2 \mathrm{H}, J=8.6 \mathrm{~Hz}, \mathrm{ArH}), 12.13(\mathrm{~s}, 1 \mathrm{H}, \mathrm{NH}) ;{ }^{13} \mathrm{C}$ NMR $\left(100 \mathrm{MHz}, \mathrm{DMSO}-d_{6}\right) \delta$ ppm 10.1, 35.1, 61.0, 98.6, 120.5, 123.9, 129.1, 135.9, 146.5, 149.2, 150.7, 161.2.

Compound 5m: IR (KBr) cm $\mathrm{cm}^{-1} 3433,3345,2190,1665,1594,1515,1395,1355,1125,1055,832$, 755; ${ }^{1} \mathrm{H}$ NMR (400 MHz, DMSO- $\left.d_{6}\right) \delta$ ppm $1.79\left(\mathrm{~s}, 3 \mathrm{H}, \mathrm{CH}_{3}\right), 4.94(\mathrm{~s}, 1 \mathrm{H}, \mathrm{CH}), 6.98\left(\mathrm{~s}, 2 \mathrm{H}, \mathrm{NH}_{2}\right)$, 7.33-7.37 (m, 1H, ArH), 7.49-7.53 (m, 2H, ArH), 7.59 (d, 2H, J=8.4 Hz, ArH), 7.80 (d, 2H, $J=8.4$ $\mathrm{Hz}, \mathrm{ArH}), 8.23$ (d, $2 \mathrm{H}, J=8.5 \mathrm{~Hz}, \mathrm{ArH})$.

\section{References}

1 (a) Mistry, P. T.; Kamdar, N. R.; Haveliwala, D. D.; Patel, S. K. (2012), Synthesis, Characterization, and In Vitro Biological Studies of Some Novel Pyran Fused Pyrimidone Derivatives. J. Heterocyclic Chem. 49, 349-357; (b) Mandour, A. H.; El-Sawy, E. R.; Ebaid, M. S.; Hassan, S. M. (2012), Synthesis and potential biological activity of some novel 3-[(Nsubstitutedindol-3-yl)methyleneamino]-6-amino-4-aryl-pyrano(2,3-c)pyrazole-5-carbonitriles and 3,6-diamino-4-( $N$-substitutedindol-3-yl)pyrano(2,3-c)pyrazole-5-carbonitriles. Acta Pharm. 62, $15-30$.

2 Kuo, S. C.; Huang, L. J.; Nakamura, H. (1984), Studies on heterocyclic compounds. 6. Synthesis and analgesic and antiinflammatory activities of 3,4-dimethyl-pyra- 2,3-c]pyrazol-6-one derivatives. J. Med. Chem. 27, 539-544.

3 Ahluwalia, V. K.; Dahiya, A.; Garg, V. (1997), Reaction of 5-amino-4-formyl-3-methyl(or phenyl)-1-phenyl-1H-pyrazoles with active methylene compounds: Synthesis of fused heterocyclic rings. Indian J. Chem. 36B, 88-90.

4 Wang, J. L.; Liu, D.; Zheng, Z. J.; Shan, S.; Han, X.; Srinivasula, S. M.; Croce, C. M.; Alnemri, E. S.; Huang, Z. (2009), Structure-based discovery of an organic compound that bind Bc1-2 protein and induces apoptosis of tumor cells. Proc. Natl. Acad. Sci. U.S.A., 97, 7124-7129.

5 Zaki, M. E. A.; Morsy, E. M.; Abdel-Motti, F. M.; Abdel-Megeid, F. M. E. (2004), The Behaviour of Ethyl 1-acetyl-4-aryl-5-cyano-3-methyl-1,4-dihydropyrano[2,3-c]pyrazol-6-ylimidoformate Towards Nucleophiles. Heterocycl. Commun. 10, 97-102.

6 (a) Zaki, M. E. A.; Saliman, H. A.; Hiekal, O. A.; Rashad, A. E. (2006), Pyrazolopyranopyrimidines as a Class of Anti-Inflammatory Agents. Z. Naturforsch., C: Biosci. 61,1-5; (b) Mandha, S. R.; Siliveri, S.; Alla, M.; Bommena, V. R.; Bommineni, M. R.; Balasubramanian, S. (2012), Eco-friendly synthesis and biological evaluation of substituted pyrano[2,3-c]pyrazoles. Bioorg. Med. Chem. Lett. 22, 5272-5278.

7 Foloppe, N.; Fisher, L. M.; Howes, R.; Potter, A.; Robertson, A. G. S.; Surgenor, A. E. (2006), Identification of chemically diverse Chk1 inhibitors by receptor-based virtual screening. Bioorg. Med. Chem. 14, 4792-4802.

8 (a) Abdelrazek, F. M.; Metz1, P.; Kataeva1, O.; Jäger, A.; El-Mahrouky, S. F. (2007), Synthesis and Molluscicidal Activity of New Chromene and Pyrano[2,3-c]pyrazole Derivatives. Arch. Pharm. Chem. Life Sci. 340, 543-548; (b) Abdelrazek, F. M.; Michael, F. A.; Mohamed. A. E. (2006), Synthesis and Molluscicidal Activity of Some 1,3,4-Triaryl-5-chloropyrazole, Pyrano[2,3c]pyrazole, Pyrazolylphthalazine and Pyrano[2,3-d]thiazole Derivatives. Arch. Pharm. Chem. Life Sci. 339, 305-312.

9 Ramiz, M. M. M.; Abdel Hafiz, I. S.; Abdel Reheim, M. A. M.; Gaber, H. M. (2012), Pyrazolones as Building Blocks in Heterocyclic Synthesis: Synthesis of New Pyrazolopyran, pyrazolopyridazine and Pyrazole Derivatives of Expected Antifungicidal Activity. J. Chin. Chem. Soc. 59, $72-80$. 
10 Wamhoff, H.; Kroth, E.; Strauch, K. (1993), Dihalogentriphenylphosphorane in der Heterocyclensynthese; $27^{1}$ : Heterokondensierte 1,2,4-Triazolo[1,5-c]pyrimidine aus Enaminonitrilen via $O$-Ethylformimide. Synthesis 11, 1129-1132.

11 (a) Hafez, E. A. A.; Elnagdi, M. H.; Elagamey, A. G. A.; Ei-Taweel, F. M. A. A. (1987), Nitriles in Heterocyclic Synthesis: Novel Synthesis of Benzo[c]coumarin and of Benzo[c]pyrano[3,2c]quinoline Derivatives. Heterocycles 26, 903-907; (b) Armetso, D.; Horspool, W. M.; Martin, N.; Ramos, A.; Seaone, C. (1989), Synthesis of Cyclobutenes by the Novel Photo- chemical Ring Contraction of 4-Substituted-2-amino-3,5- dicyano-6-phenyl-4H-pyrans. J. Org. Chem. 54, 30693072 .

12 Junek, H.; Aigner, H. (1973), Synthesen mit Nitrilen, XXXV: Reaktionen von Tetracyanäthylen mit Heterocyclen. Chem. Ber. 106, 914-921.

13 Otto, H. H. (1974), Synthesis of Some 4H-Pyrano[2.3-c]pyrazoles. Arch. Pharm. 307, 444-447.

14 (a) Sharanin, Y. A.; Shcherbina, L. N.; Sharanina, L. G.; Puzanova, V. V. (1983), Nitrile cyclization reactions, VI: Synthesis of 2-amino-4-(2-furyl)-4H-pyrans. Zh. Org. Khim. 19, 164173; (b) Shestopalov, A. M.; Yakubov, A. P.; Tsyganov, D. V.; Emel'yanova, Y. M.; Nesterov, V. N. (2002), Synthesis of substituted 6-amino-4-aryl-5-cyano-2H,4H-pyrano[2,3-c]pyrazoles. Crystal and molecular structure of 6-amino-5-cyano-3-methyl-4-(2',4',6'-triethylphenyl)-2 $\mathrm{H}, 4 \mathrm{H}$ pyrano[2,3-c]pyrazole. Chem. Heterocycl. Compd. 38, 1180-1189; (c) Jin, T.-S.; Zhao, R.-Q.; Li, T.-S. (2006), An one-pot three-component process for the synthesis of 6-amino-4-aryl-5-cyano-3methyl-1-phenyl-1,4-dihydropyrano[2,3-c]pyrazoles in aqueous media. Arkivoc xi, 176-182; (d) Jin, T.-S.; Wang, A.-Q.; Cheng, Z.-L.; Zhang, J.-S.; Li, T.-S. (2005), A Clean and simple synthesis of 6-amino-4-aryl-5-cyano-3-methyl-1-phenyl-1,4-dihydropyrano[2,3-c]pyrazole in water. Synth. Commun. 35, 137-143; (e) Thumar, N. J.; Patel, M. P. (2009), Synthesis and in vitro antimicrobial evaluation of $4 H$-pyrazolopyran, -benzopyran and naphthopyran derivatives of $1 H$-pyrazole. Arkivoc 13, 363-380; (f) Dawane, B. S.; Yemul, O. S.; Chobe, S. S.; Mandawad, G. G.; Kamble, R. D.; Shinde, A. V.; Kale, V. S.; Hurne, A. O.; Pawde, M. A.; Kale, M. P.; Desai, N. P.; Salgare, R. R.; Patil, M. B.; Mundhe, S. N.; Chavan, S. R. (2011), One-pot multicomponent synthesis and antimicrobial evaluation of some novel pyrano-[2,3-c]-pyrazoles derivatives. Der Pharma Chem. 3 (3), 300-305; (g) Mohamed, N. R.; Khaireldin, N. Y.; Fahmyb, A. F.; El-Sayeda, A. A. (2010), Facile synthesis of fused nitrogen containing heterocycles as anticancer agents. Der Pharma Chem. 2 (1), 400-417; (h) Prajapati, S. P.; Patel, D. P.; Patel, P. S. (2012), Synthesis, Characterization and Antimicrobial activity of 6-amino-4-(substitutedphenyl)-1-(2,4dinitrophenyl)-3-methyl-1,4-dihydropyrano[2,3-c]pyrazole-5-carbonitrile derivatives. J. Chem. Pharm. Res. 4, 2652-2655; (i) Shi, D.; Mou, J.; Zhuang, Q.; Niu, L.; Wu, N.; Wang, X. (2004), Three-Component one-pot synthesis of 1,4-dihydropyrano[2,3-c]pyrazole derivatives in aqueous media. Synth. Commun. 34, 4557-4563; (j) Xiang, W. S.; Wei, W.; Tai, T. L. (2005), Synthesis of 1, 4-Dihydropyrano[2,3-c]pyrazole derivatives with no catalyst under ultrasound irradiation. E-J. Chem. 2, 121-125.

15 (a) Shestopalov, A. M.; Emeliyanova, Y. M.; Shestopalov, A. A.; Rodinovskaya, L. A.; Niazimbetova, Z. I.; Evans, D. H. (2002), One-Step Synthesis of Substituted 6-Amino-5cyanospiro-4-(piperidine-4')-2H,4H-dihydropyrazolo[3,4-b]pyrans. Org. Lett. 4, 423-425; (b) Shestopalov, A. M.; Emeliyanova, Y. M.; Shestopalov, A. A.; Rodinovskaya, L. A.; Niazimbetova, Z. I.; Evans, D. H. (2003), Cross-condensation of derivatives of cyanoacetic acid and carbonyl compounds. Part 1: Single-stage synthesis of 1'-substituted 6-amino-spiro-4(piperidine-4')-2H,4H-pyrano[2,3-c]pyrazole-5-carbonitriles. Tetrahedron 59, 7491-7496.

16 Vasuki, G.; Kandhasamy, K. (2008), Rapid four-component reactions in water: synthesis of pyranopyrazoles. Tetrahedron Lett. 49, 5636-5638.

17 Siddekha, A.; Nizam, A.; Pasha, M. A. (2011), An efficient and simple approach for the synthesis of pyranopyrazoles using imidazole (catalytic) in aqueous medium, and the vibrational spectroscopic studies on 6-amino-4-(4-methoxyphenyl)-5-cyano-3-methyl-1-phenyl-1,4dihydropyrano[2,3-c]pyrazole using density functional theory. Spectrochim. Acta A, 81, 431-440. 
18 El-Assaly, S. A. (2011), A simple and clean method for four-component synthesis of pyrano[2,3c]pyrazole derivatives. Der Pharma Chem. 3 (5), 81-86.

19 Gogoi, S.; Zhao, C.-G. (2009), Organocatalyzed enantioselective synthesis of 6-amino-5cyanodihydropyrano[2,3-c]pyrazoles. Tetrahedron Lett. 50, 2252-2255.

20 Kanagaraj, K.; Pitchumani, K. (2010), Solvent-free multicomponent synthesis of pyranopyrazoles: per-6-amino-b-cyclodextrin as a remarkable catalyst and host. Tetrahedron Lett. 51, 3312-3316.

21 Ebrahimi, J.; Mohanndi, A.; Pakjoo, V.; Bahramzadeh, E.; Habibi, A. (2012), Highly efficient solvent-free synthesis of pyranopyrazoles by a Brønsted-acidic ionic liquid as a green and reusable catalyst. J. Chem. Sci. 124, 1013-1017.

22 Khurana, J. M.; Chaudhary, A. (2012), Efficient and green synthesis of $4 H$-pyrans and $4 H$ pyrano[2,3-c]pyrazoles catalyzed by task-specific ionic liquid [bmim] OH under solvent-free conditions. Green Chem. Lett. Rev. 5, 633-638.

23 Mecadon, H.; Rohman, M. R.; Kharbangar, I.; Laloo, B. M.; Kharkongor, I.; Rajbangshi, M.; Myrboh, B. (2011), L-Proline as an efficient catalyst for the multi-component synthesis of 6amino-4-alkyl/aryl-3-methyl-2,4-dihydropyrano[2,3-c]pyrazole-5-carbonitriles in water. Tetrahedron Lett. 52, 3228-3231.

24 Chavan, H. V.; Babar, S. B.; Hoval, R. U.; Bandgar, B. P. (2011), Rapid one-pot, four component synthesis of pyranopyrazoles using heteropolyacid under solvent-free condition. Bull. Korean Chem. Soc. 32, 3963-3966.

25 Reddy, M. B. M.; Jayashankara, V. P.; Pasha, M. A. (2010), Glycine-catalyzed efficient synthesis of pyranopyrazoles via one-pot multicomponent reaction. Synth. Commun. 40, 2930-2934.

26 Kathrotiya, H. G.; Patel, R. G.; Patel, M. P. (2012), Microwave-assisted multi-component synthesis of indol-3-yl substituted pyrano[2,3-c]pyrazoles and their antimicrobial activity. J. Serb. Chem. Soc.77, 983-991.

27 Wu, M.-S.; Kong, D.-L.; Zhang, X.-Z. (2011), 6-Amino-3-methyl-4-(3-nitrophenyl)-1-phenyl1H,4H-pyrano[2,3-c]pyrazole-5-carbonitrile. Acta Cryst. E67, o1454-o1455.

28 Reddy, M. B. M.; Pasha, M. A. (2012), One-pot, multicomponent synthesis of 4H-pyrano[2,3c]pyrazoles in water at $25^{\circ} \mathrm{C}$. Indian J. Chem. 51B, 537-541.

29 Khurana, J. M.; Nand, B.; Kumar, S. (2011), Rapid synthesis of polyfunctionalized pyrano[2,3c]pyrazoles via multicomponent condensation in room-temperature liquids. Synth. Commun. 41, 405-410.

30 Shinde, P. V.; Gujar, J. B.; Shingate, B. B.; Shingare, M. S. (2012), Silica in Water: A Potentially Valuable Reaction Medium for the Synthesis of Pyrano[2,3-c]pyrazoles. Bull. Korean Chem. Soc. 33, 1345-1348.

31 Babaie, M.; Sheibani, H. (2011), Nanosized magnesium oxide as a highly effective heterogeneous base catalyst for the rapid synthesis of pyranopyrazoles via a tandem four-component reaction. Arabian J. Chem. 4, 159-162.

32 Azzam, S. H. S.; Pasha, M. A. (2012), Simple and efficient protocol for the synthesis of novel dihydro-1H-pyrano[2,3-c]pyrazol-6-ones via a one-pot four-component reaction. Tetrahedron Lett. 53, 6834-6837.

$33 \mathrm{Wu}$, M.; Feng, Q.; Wan, D.; Ma, J. (2013), CTACl as Catalyst for four-component one-pot synthesis of pyranopyrazole derivatives in aqueous medium. Synth. Commun. 43, 1721-1726.

34 Nagarajan, A. S.; Reddy, B. S. R. (2009), Synthesis of Substituted Pyranopyrazoles under Neat Conditions via a Multicomponent Reaction. Synlett 2002-2004.

35 Bihani, M.; Bora, P. P.; Bez, G. (2013), A catalytic-free synthesis of 6-Amino-4 Alkyl/Aryl-3methyl-2,4-dihydropyrano[2,3-c]pyrazole-carbonitrile in Aqueous Medium. J. Chem. 2013, Article ID 920719, 8 pages, doi:10.1155/2013/920719.

36 Zhou, J.-F.; Tu, S.-J.; Zhu, H.-Q.; Zhi, S.-J. (2002), A facial one-pot synthesis of pyrano[2,3c]pyrazole derivatives under microwave irradiation. Synth. Commun. 32, 3363-3366. 
37 Guo, S.-B.; Wang, S.-X.; Li, J.-T. (2007), D,L-Proline-catalyzed one-pot synthesis of pyrans and pyrano[2,3-c]pyrazole derivatives by a grinding method under solvent-free conditions. Synth. Commun. 37, 2111-2120.

38 Pirrung, M. C. (2006), Acceleration of Organic Reactions through Aqueous Solvent Effects. Chem. Eur. J. 12, 1312-1317.

39 Chitra, S.; Paul, N.; Muthusbramanian, S.; Manisankar, P. (2011), A facile, water mediated, microwave-assisted synthesis of 4,6-diaryl-2,3,3a,4-tetrahydro- $1 H$-pyrido[3,2,1-jk]carbazoles by a domino Fischer indole reaction-intramolecular cyclization sequence. Green Chem. 13, 2777-2785.

40 Organic Reactions in Water: Principles, Strategies and Applications, editor: Lindström, U. M. Blackwell Publishing: Oxford, U. K., 2007; p. 60.

41 Comprehensive Organic Reactions in Aqueous Media, editors: Li, C.-J. Chan, T.-H., 2nd ed.; John Wiley \& Sons, Hoboken, New Jersey, U. S. A. 2007, p. 2.

42 Lindstrom, U. M. (2002), Stereoselective organic reactions in Water. Chem. Rev. 102, 2751-2772.

43 Candeias, N. R., Cal, P. M. S. D., Andre, V.; Duarte, M. T.; Veiros, L. F.; Gois, P. M. P. (2010), Water as the reaction medium for multicomponent reactions based on boronic acids. Tetrahedron 66, 2736-2745.

44 Moorhoff, C. M.; Schneider, D. F. (1998), Sodium benzoate as a mild base catalyst for the tandem Michael-Aldol self-condensation of $\gamma, \beta$-unsaturated $\alpha$-ketoesters. Monatsh. Chem. 129, 409-417.

45 Liu, Q.; Zhang, Y.-N. (2011), One-pot synthesis of 3-methyl-4-arylmethylene-isoxazol-5(4H)ones catalyzed by sodium benzoate in aqueous media: A green chemistry strategy. Bull. Korean Chem. Soc. 32, 3559-3560.

46 Liu, Q.; Ai, H.-M. (2012), Sodium benzoate as s green, efficient, and recyclable catalyst for Knoevenagel condensation. Synth. Commun. 42, 3004-3010.

47 D. K. Yadav, M. A. (2012), Quraishi, Electrochemical investigation of substituted pyranopyrazoles adsorption on mild steel in acid solution. Ind. Eng. Chem. Res. 51, 8194-8210.

48 Saha, M.; Pal, A. K. (2012), Palladium (0) Nanoparticles: A Novel and Reusable Catalyst for the Synthesis of Various Pyran Derivatives. Adv. Nanopart. 1, 61-70. 